Int. J. Dev. Biol. 53: 269-274 (2009)

doi: $10.1387 / \mathrm{ijdb} .082686 \mathrm{sk}$

\title{
Chemical genomics: a key to the epigenome An interview with Minoru Yoshida
}

\author{
SAADI KHOCHBIN* \\ Institut Albert Bonniot, La Tronche Cedex, Grenoble, France
}

\begin{abstract}
The identification and characterization of the first potent histone deacetylase inhibitors constituted a major step, which not only gave a key to researchers worldwide to tackle the unknown universe of cell signalling by protein lysine acetylation, but also opened the way for the development of large series of molecules with important therapeutic properties. Minoru Yoshida, who played a critical role in characterizing the fist potent and specific histone deacetylase inhibitor, trichostatin A, reveals here how and why his work led to this discovery. He also comments on his other outstanding contributions and gives his opinion on the impact of chemical genomics as a key to open the mysteries of the epigenome.
\end{abstract}

KEY WORDS: CRM1, leptomycin B, HDAC6, trapoxin, cancer, splicing, RIKEN

What is your present position and how did you reach this position? Which particular steps and choices you made during your professional life would you consider critical?

Currently I am Director of the Chemical Genomics Research Group as well as the Chief Scientist of the Chemical Genetics Laboratory in the RIKEN Advanced Science Institute. RIKEN is a government-funded research institute covering physics, chemistry, biology and medical sciences. Before moving to RIKEN in 2002, I worked for the University of Tokyo for 16 years as Assistant and Associate Professor, during which time my group succeeded in isolating several microbial metabolites with very unique biological activities such as the induction of cell differentiation and cell cycle arrest and in identifying their cellular targets.

The University of Tokyo is one of the best universities in Japan, but RIKEN offered me the opportunity to have a relatively large research group including a number of tenured research staff members. At that moment, I wanted to expand my chemical biology research to chemical genomics and proteomics, aiming at the systematic identification of drug targets and involved cellular pathways. These new research directions also included proteomics of acetylated proteins using histone deacetylase (HDAC) inhibitors and its first outcome was the identification of HDAC6 as the tubulin deacetylase in 2002. I think therefore that the move to RIKEN was a critical step in my career.

The discovery of the first potent and specific inhibitors of histone-deacetylases, i. e., trichostatin A (TSA), has greatly contributed to our understanding of modern epigenetics.
Could you highlight the major steps in the identification and characterizations of these molecules?

About 20 years ago, when I was a graduate student of the Laboratory of Fermentation and Microbiology, University of Tokyo, headed by Prof. Teruhiko Beppu, I discovered that TSA, which was then known for its antibiotic activity, was a potent inducer of erythroleukemia cell differentiation.

After World War II, great efforts have been conducted in Japan for the discovery of microbial metabolites and other natural products having antibiotic activity. The laboratory of Prof. Beppu focused on applied microbiology, which included drug discovery from the microbial origin. Because I was interested in cancer therapy, I started a research in the field of the so-called natural product chemistry to isolate novel compounds with differentiationinducing activity. I used Friend murine erythroleukemia cells (MEL) as a model (Fig. 1), which can be differentiated to reticulocytes by a high concentration of dimethylsulfoxide. At that moment, there was no potent inducer that was active at low concentrations. My investigations showed that TSA was the first compound capable of inducing differentiation at low nanomolar concentrations (Yoshida et al., 1987). The goal of traditional natural product chemistry was to isolate a novel compound and to elucidate its chemical structure. However, since the structure of

Abbreviations used in this paper: HDAC, histone deacetylase; LMB, leptomycin B; MEL, murine erythroleukemia; NES, nuclear export signal; TSA, trichostatin A.

\footnotetext{
*Address correspondence to: Saadi Khochbin. Institut Albert Bonniot, Domaine de La Merci, La Tronche Cedex 38706 , Grenoble, France. Tel.: +33-4-7654-9583. Fax: +33-4-7654-9595. e-mail: khochbin@ujf-grenoble.fr

Published online: 24 April 2009.
} 
TSA was known, as a natural product chemist, I had to move on to another compound with a novel structure. But the cellular phenotypes induced by TSA such as differentiation and cell cycle arrest appeared so attractive to me that I decided to pursue my investigations into their cellular targets. Prof. Beppu allowed me to continue my research on TSA. He said "you can do everything as long as you feel that your findings will be outstanding". Thus I gave up my career as a natural product chemist to become a chemical biologist. This was the Rubicon of my life in science.

A clue to the identification of HDACs as TSA targets was its ability to induce $\mathrm{G} 1$ and $\mathrm{G} 2$ arrest in the cell cycle of normal rat fibroblasts (Yoshida and Beppu, 1988). In 1981, Paul Nurse, who later became a Nobel laureate, identified cdc2 as a master gene regulating both $\mathrm{G} 1$ and $\mathrm{G} 2$ in the fission yeast cell cycle (Nurse and Bissett, 1981). The cdc2 gene product can phosphorylate histone $\mathrm{H} 1$. In 1987, the year we published our first paper on the differentiation-inducing activity of TSA, his group
A<smiles>CC(/C=C/C(=O)NO)=C\[C@@H](C)C(=O)c1ccc(N(C)C)cc1</smiles>

Normal rat fibroblast cells

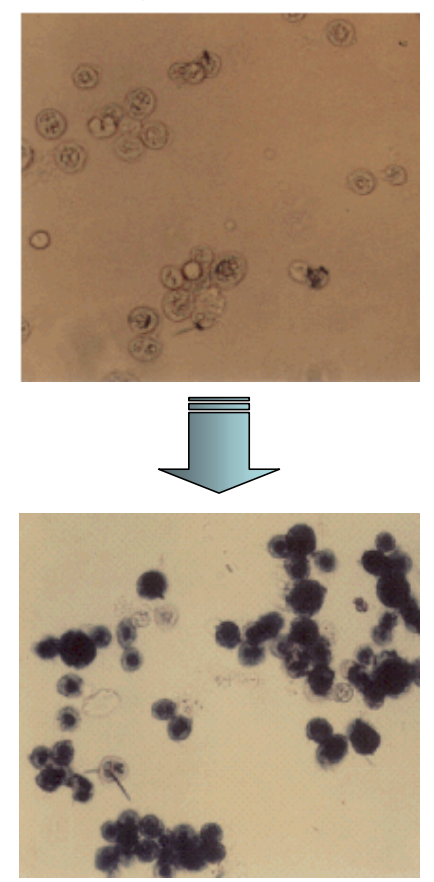

Differentiated, hemoglobin-positive cells

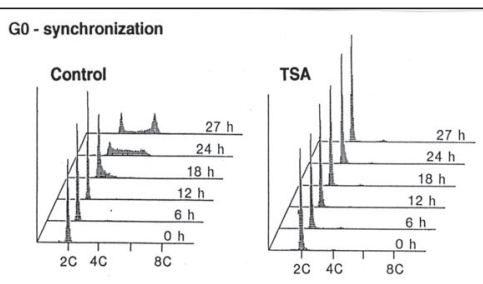

Early S - synchronization
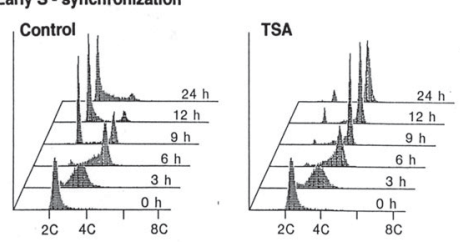

TSA Removal

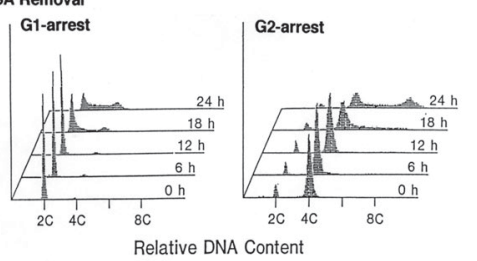

Reversible G1 and G2 arrest
Fig. 1. Induction of differentiation in erythroleukemia cells and reversible G1 and G2 arrest in normal rat fibroblast cells. Friend leukemia cells are known to undergo differentiation after 2\% DMSO treatment. TSA was rediscovered during the course of screening for biologically active microbial products as a potent inducer of differentiation. (A) A low nanomolar concentration of TSA induced accumulation of differentiated, hemoglobin-positive cells detected by benzidine staining. (B) Normal rat 3 Y 1 fibroblasts were synchronized by serum deprivation (GO) or hydroxyurea treatment (early S). TSA reversibly blocked the G1/S and G2/M transition in synchronous cultures. Interestingly, after the removal of TSA, G2 arrested cells resumed cell cycle and started DNA synthesis, consequently becoming tetraploid cells. showed that a homologue of $c d c 2$ also controls the onset of mitosis in human cells (Lee and Nurse, 1987). The excitement ciated with the discovery of important cell cycle regulators prontrol and histone a indirectly inhibited in vivo histone phosphorylation in mammalian cells, although it did not inhibit in vitro Histone $\mathrm{H} 1$ kinase this finding as a cue, we biochemically showed that TSA proved that HDACs were the primary targets of the TSA-

In your opinion, what is the impact of these molecules on the discovery of HDACs themselves, and on the determina-

A few years after our work on TSA, we found that trapoxin, a fungal cyclic tetrapeptide, also inhibited HDACs. In contrast to the reversible inhibition by TSA, trapoxin covalently bound to HDACs. These two compounds opened the door to a new research area on chromatin modifications and functions. Indeed, trapoxin, which can covalently bind HDACs, was used by Schreiber's group as a specific trap to isolate and clone the first HDAC in 1996, now known as HDAC1 (Taunton et al., 1996). Since then, a number of related enzymes were identified based on the sequence similarity to HDAC1.

It is now established that HDACs constitute a multi-enzyme family, which is categorized into three classes (Khochbin et al., 2001). Class I and II enzymes are zinc-dependent and can be inhibited by TSA, whereas class III enzymes are NADdependent and insensitive to TSA. Even within class $\mathrm{I} / \mathrm{II}$ enzymes, there are differences in the sensitivity to HDAC inhibitors. In particular, HDAC6 was resistant to trapoxin. This differential sensitivity was used for the identification of HDAC6 substrates. Indeed, alpha-tubulin was detected as an acetylated protein, whose in vivo acetylation level was increased by TSA but not trapoxin (Matsuyama et al., 2002).

\section{How did the early characterization of these potent inhibitors contribute to the design of the new generations of specific HDAC inhibi- tors (HDACis)?}

Now it is well known that each class I/II HDAC enzyme has a zinc ion in the catalytic pocket, which plays a pivotal role in activating a water molecule that attacks the carbonyl carbon for the acetamide cleavage similar to the metal protease-like reaction. However, of course, there was no information on the structure of the HDACs, at the moment I found the HDAC inhibitory activity of TSA, although we speculated that HDACs are metal enzymes, because the hydroxamic 
acid of TSA is a strong metal chelator. This notion was verified by the first structural analysis of an HDAC prototype enzyme from a bacterium (Finnin et al., 1999). Indeed, the hydroxamic acid moiety in TSA chelates the zinc in the tube-like deep active-site pocket. On the other hand, an aromatic group of TSA acts as a cap to pack the inhibitor at the rim of the pocket. Thus, TSA is an ideal structure to inhibit HDACs. The presence of the hydroxamic acid is exceptional in natural products. Thus, in this story of the God's dispensation, I believe that the real originality came from the evolution of the TSA-producing microorganism in soil, and what the researchers did was only to discover and highlight their perfect structural and functional properties.

It should however be noted that the biggest clinical impact of HDAC inhibitors occurred independently from us by the development of another class of differentiation inducers for MEL cells. The research team of Memorial Sloan Kettering Cancer Centre and Columbia University invented SAHA (Vorinostat) as a potent inducer of MEL cells. Later, they revealed that SAHA is also a HDAC inhibitor (Richon et al., 1998). The clue to the understanding of SAHA's action was its similarity to TSA in terms of structure and activity. SAHA also binds the enzyme by interacting with the zinc (Finnin et al., 1999). An aromatic ring with a 5-6 carbon-length spacer was also important for the inhibitory activity. Thus, the basic structure of HDAC inhibitor should consist of a zinc-or active site residue-interacting moiety, a spacer, and a cap group that interacts with the region surrounding the entrance of the enzyme pocket. Almost all potent HDAC inhibitors abide by this rule. However, FK228, a bicyclic depsipeptide containing an intramolecular disulfide bond apparently does not have such a structure (Nakajima et al., 1998). We showed that FK228 itself is inactive but is activated by intracellular reducing activity after its uptake by the cells. The reduction of the disulfide bond in FK228 results in the formation of sulfhydryl groups that can interact with the active-site zinc. The reduced FK228 with the free thiol groups was too unstable to exhibit a biological activity, so FK228 acts as a natural prodrug (Furumai et al., 2002). This feature may contribute to its good clinical efficacy. SAHA has been approved for the treatment of cutaneous T-cell lymphoma in 2006, and several other drug candidates including FK228 are currently investigated clinically.

Anti-cancer therapy now appears as a major application field for HDACis. What do we know about the molecular basis of their action on cancer, what are the other pathologies for which these inhibitors may be relevant and how do you think this will evolve in the future?

Among the anticancer drugs, HDAC inhibitors are categorized into the molecular target drugs, most of which are currently inhibitors of specific protein kinases responsible for pathogenesis. In contrast to the protein kinase inhibitors, however, the mechanism underlying the selective cytotoxicity of HDAC inhibitors to tumour cells is still unclear. It is suggested

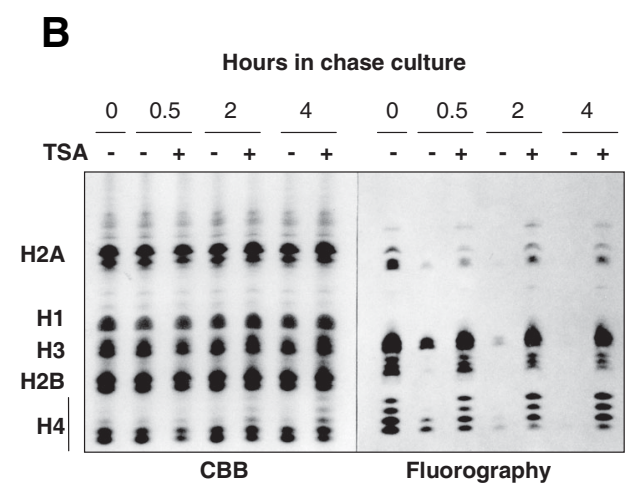

CBB

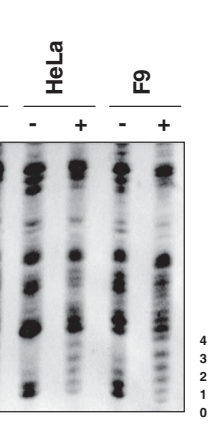

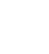

Fig. 2. Induction of histone hyperacetylation in cells by TSA. TSA induced the accumulaelectrophoresis, which allows separation of each histone molecule according to its level of acetylation (A). Incubation of cells with labelled acetate results in the incorporation of the acetyl group into the core histones, which can be visualized by fluorography. In the chase experiment, after washing the labelled acetate, acetylated histones rapidly disappeared in SA but this deacetylation was completely blocked by TSA (B).

that the extrinsic pathway for apoptosis is specifically induced by HDAC inhibitors (for instance Fas, FasL, and TRAIL gene expression has been reported to be upregulated after HDACi treatment). Interestingly, although histone acetylation may regulate global gene expression, a relatively small subset of genes are upregulated by HDAC inhibitors. Nevertheless, many tumour suppressor genes that are silenced in tumour cells are reported to be reactivated by HDAC inhibitors. Importantly, histone deacetylation is associated with oncogenic transcription factors as well as with DNA methylation that occurs in the $\mathrm{CpG}$ islands in the promoter region of some critical genes (Nan et al., 1998). Therefore, it seems possible that inhibition of HDACs results in the reversal of aberrantly silenced gene expression induced by oncogenic dysfunction of chromatin. If so, HDAC inhibitors should be considered as very attractive anticancer drugs, and indeed with this respect they have already exhibited considerable efficacy (Marks et al., 2001).

Recently, HDAC inhibitors have also been reported to show therapeutic activities against neurodegenerative and inflammatory diseases such as articular rheumatism, which are associated with aging. Unlike anticancer drugs, the therapeutic molecules against age-related, chronic diseases need to be safer and less toxic. Accordingly, the next generation of HDACi should be subtype-specific inhibitors, taking into account the fact that eleven different zinc-dependent HDAC enzymes exist in human, which may have distinct and specific functions (Khochbin et al., 2001; Yang and Seto, 2008). Lessons from protein kinase inhibitors highlight the importance of target enzyme selectivity in successful chemotherapy. However, information currently available on the HDAC structures is insufficient for the rational design of the subtype-specific inhibitors. I suppose that the cap group touching the enzyme surface and the zinc-interacting group constitute important elements in designing HDAC-specific inhibitors. The situation may however be a more complex one than the case of protein kinases, because multiple HDAC enzymes assemble into a limited number of corepressor complexes. A variety of different oncogenic transcriptional regulators use the common corepressor 
complex. Therefore, it is still obscure whether specific inhibition of a particular enzyme could be associated with particular therapeutic effects. It is probably also important to search for agents that inhibit the corepressor complex assembly or protein-interaction between HDACs and transcriptional regulators.

Important efforts have been employed for the identification/ characterization of HDACis. What about HDAC activators? Do you see any interest in developing this type of molecule?

Because protein acetylation controls various cellular functions in both positive and negative manners, it is probable that reduced histone acetylation by the HDAC activator profoundly affects cellular phenotypes. Indeed, we saw a decrease in histone acetylation level by some inhibitors of energy metabolism, probably due to the decrease in the cellular acetyl-CoA levels. A direct activator for the HDAC enzyme would however be more interesting. In particular, an activator for HDAC6, a subtype enzyme catalyzing cytoplasmic substrates such as alpha-tubulin and Hsp90, could be clinically important, because this enzyme is involved in degradation of unfolded proteins, whose accumulation causes a variety of diseases including neurodegenerative diseases (Boyault et al., 2007; Pandey et al., 2007).

What future do you see, in terms of applications, for specific class III HDAC inhibitors/activators?

Class III HDAC family enzymes, which are similar to the yeast Sir2 gene product and thus named Sirtuins, are recently drawing much attention. Sirtuins require NAD but not a zinc ion for their activity, and therefore are insensitive to TSA. Because NAD is a key molecule for cellular redox and metabolic activity, it is suggested that Sirtuin enzymes regulate cell metabolism. Indeed, resveratrol, a polyphenol enriched in red wine, has been shown to activate Sirt1, prevented metabolic syndromes and prolonged the life span from yeast to mice (Guarente, 2007; Guarente and Picard, 2005). Therefore, in recent years, screening for Sirtuin inhibitors/activators is actively carried out (Lavu et al., 2008). I am personally interested in the compounds regulating Sirt3, because Sirt3 is localized in mitochondria and may control energy metabolism (Onyango et al., 2002; Schwer et al., 2002).

You were also involved in another startling discovery, that of leptomycin B (LMB). Could you let us know how your early observations of defects in fission yeast higher order chromosome structure has led to the characterization of a major nuclear export system?

Yes, it was a really exciting story. LMB was discovered in our laboratory as an antifungal antibiotic, which inhibited the growth of a subset of fungal species including fission yeast Schizosaccharomyces pombe at nanomolar concentrations. Surprisingly, however, the budding yeast Saccharomyces cerevisiae was totally insensitive to LMB, suggesting the existence of a specific target molecule in the LMB-sensitive microorganisms. We succeeded in identifying Crm1 as the LMB target by cloning the LMB-resistance gene from an LMB-resistant mutant strain of S. pombe (Nishi et al., 1994). Crm1 was originally identified by Prof. Yanagida, Kyoto University, as an essential gene involved in chromosome region maintenance (Adachi and Yanagida, 1989). We noticed that mutants defective in Crm1 showed exactly the same phenotypes as the wild-type cells treated by LMB. These

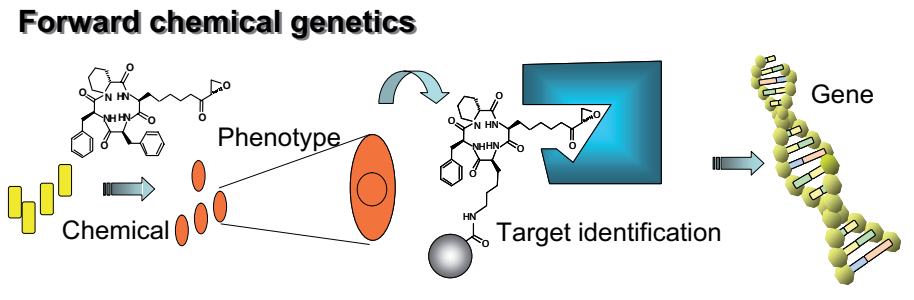

Reverse chemical genetics
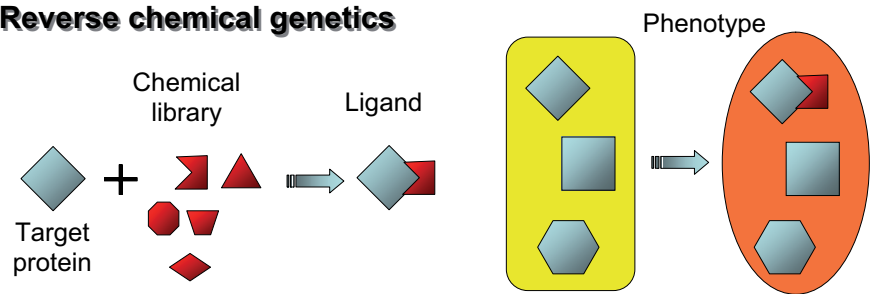

Fig. 3. What is chemical genetics? Chemical genetics parallels classical genetics. Whereas the latter searches for the mutational basis of a phenotype, chemical genetics consists in looking for the target of a specific compound responsible for a given phenotype. Similar to the reverse genetic approach, there is also a reverse strategy in chemical genetics. A specific ligand for a particular protein of interest can be discovered using a chemical library and the phenotype induced by the ligand can be analysed.OWhile mutations target genes, chemicals target proteins. Therefore, a phenotype can easily be obtained using chemicals even if cells have multiple genes with redundant functions. Furthermore, if the target is clinically important, the chemical presents the potential of becoming a therapeutic drug. Therefore, chemical genetics is now regarded as one of the important approaches in the post-genomic era.

observations strongly pointed to Crm1 as the molecular target of LMB. However, the molecular function of Crm1 was unknown at that moment. Amazingly a breakthrough occurred after a poster presentation by the Sando Pharmaceutical company group in the annual meeting of American Society for Cell Biology in 1996. This poster showed that LMB was found during the course of a screening for compounds capable of inhibiting nuclear export of HIV Rev. Rev is an essential viral protein for the nuclear export of the HIV RNA genome into the cytoplasm where the virion assembly occurs. A leucine-rich nuclear export signal (NES) was identified in Rev, which was proposed to be a signal sequence recognized by a putative cellular factor responsible for nuclear protein export. However, this nuclear export remained unknown and there was fierce international competition to identify the factor. Together, data from this poster showing that LMB inhibited Rev nuclear export and our own data showing that Crm1 was the target of LMB, strongly pointed to Crm1 as the long awaited nuclear export factor. This hypothesis was soon verified by a couple of groups including ours (Fornerod et al., 1997; Fukuda et al., 1997; Kudo et al., 1997; Ossareh-Nazari et al., 1997). Furthermore, we showed that LMB covalently bound to a single cysteine residue in the central conserved region of Crm1 by a Michael-type addition (Kudo et al., 1999). This binding prevented proteinprotein interaction between Crm1 and NES-bearing proteins. Importantly, the cysteine residue was conserved in Crm1 of all higher eukaryotes, but not found in that in $S$. cerevisiae or Aspergillus, which are LMB-resistant microorganisms. Thus, the single residue in Crm1 was the major determinant of the LMBsensitivity. Because Crm1 is essential for the proliferation of all eukaryotes, it is difficult to test the subcellular localization of a 
given protein after Crm1 knock-out or knock-down. Accordingly, LMB proved to be a really great tool to monitor the subcellular localization of a variety of proteins and to test the involvement of $\mathrm{Crm} 1$ in their nuclear export. Thanks to LMB, now researchers can easily test the presence of a functional NES in a protein.

\section{Epigenetics appears as one the most "drugable"} fields in biology. In your opinion, which epigenetic function(s) should be more specifically targeted, in terms of new drug discovery? Why?

Discovery of the drug that controls epigenetics is one of the major challenges in modern chemical biology. Chromatin modifications ensure the correct expression pattern of many genes and prevent their ectopic expression in differentiated tissues (Delcuve et al., 2009; Seigneurin et al., 1995). The unique gene expression pattern in a cell lineage may be inherited through the maintenance of specific chromatin modification patterns, although the mechanism of inheritance is still largely unknown. Therefore, compounds specifically active on epigenetic functions should certainly be useful for understanding the complicated underlying mechanisms. Furthermore, aberrant epigenetic regulations are suggested to be involved in age-related diseases such as cancer, Alzheimer disease, and rheumatoid arthritis. It seems possible that HDAC inhibitors partly affect the epigenetic functions and they have indeed been reported to have a therapeutic potential in the abovementioned diseases. It is probable that not only HDACs but also other enzymes mediating chromatin modifications would become under control by use of small molecules in the future. The proteinprotein interactions between key epigenetic regulators are also functionally very important and may provide good targets for future drug development. The long-term goal would be the reversal or tuning of aberrant epigenetic signalling occurring in the tissues by the combination of such small molecules.

Your approach, in contrast to now largely-used high-throughput screening (HTS), was oriented towards the discovery of the biological targets of specific biomolecules. Have you observed interesting biological effects of such molecules, for which the targets have not been identified yet?

Like classical genetics, there are two ways to proceed in chemical genetics, forward and reverse (Fig. 3). Forward chemical genetics starts from identification of a specific chemical and its goal is to identify the molecular target responsible for the cellular phenotype. On the other hand, reverse chemical genetics focuses on a particular protein of interest, for which inhibitor/ activator should be screened from a chemical library. By using thus obtained small molecules, the cellular phenotype will be analyzed to understand the role played by the protein. Obviously, both directions are important. In my research history, however, I have considered forward chemical genetics to be more important, because the effort for the target identification resulted in the unexpected finding of novel regulatory factors such as HDAC and

Crm1. In this sense, we have recently added another surprising example of the drug target using forward chemical genetics. We identified SF3b, a subcomplex in the spliceosome component U2 snRNP, as the target of an anticancer natural product FR901464 (Kaida et al., 2007). FR901464 was originally discovered as the agent inducing viral promoter activation. The apparent phenotype induced by the compound was quite similar to that of HDAC inhibitors. However, it did not inhibit HDACs. Using an stable derivative of FR901464, named spliceostatin A (Fig. 4), we showed that it binds SF3b and causes a leakage of pre-mRNA into the cytoplasm, which leads to the translation of unspliced mRNAs leading to the generation of aberrant proteins. Our conclusion was that SF3b is involved not only in the splicing reaction but also in the nuclear retention of pre-mRNAs. However, there are several yet unsolved questions about the phenotypes induced by spliceostatin A. For instance, it is still unclear how spliceostatin A upregulates viral promoter activity. Although the studies are still in progress, our preliminary data suggest that the accumulation of pre-mRNAs as a result of splicing inhibition, causes dramatic changes in chromatin modifications and epigenetic status. Unraveling the tangled relationship between splicing and epigenetics is the next important subject, which will be approached using spliceostatin A.

\section{REFERENCES}

ADACHI Y. and YANAGIDA M. (1989). Higher order chromosome structure is affected by cold-sensitive mutations in a Schizosaccharomyces pombe gene $\mathrm{crm} 1^{+}$which endodes a 115-kD protein preferentially localized in the nucleus and at its periphery. J. Cell Biol. 108: 1195-1207. 
BOYAULT, C., ZHANG, Y., FRITAH, S., CARON, C., GILQUIN, B., KWON, S. H., GARRIDO, C., YAO, T. P., VOURC'H, C., MATTHIAS, P., and KHOCHBIN, S. (2007). HDAC6, at the crossroads between cytoskeleton and cell signaling by acetylation and ubiquitination. Genes Dev. 21: 2172-81.

DELCUVE, G. P., RASTEGAR, M., and DAVIE, J.R. (2009). Epigenetic control. J. Cell. Physiol. 219: 243-50.

FINNIN, M. S., DONIGIAN, J. R., COHEN, A., RICHON, V. M., RIFKIND, R. A., MARKS, P. A., BRESLOW, R., and PAVLETICH, N.P. (1999). Structures of a histone deacetylase homologue bound to the TSA and SAHA inhibitors. Nature 401: 188-193.

FORNEROD, M., OHNO, M., YOSHIDA, M. and MATTAJ, I.W. (1997). CRM1 is an export receptor for leucine-rich nuclear export signals. Cell 90: 1051-1060.

FUKUDA, M., ASANO, S., NAKAMURA, T., ADACHI, M., YOSHIDA, M., YANAGIDA, M., and NISHIDA, E. (1997). CRM1 is responsible for intracellular transport mediated by the nuclear export signal. Nature 390: 308-311.

FURUMAI, R., MATSUYAMA, A., KOBASHI, N., LEE, K.-H., NISHIYAMA, M., NAKAJIMA, H., TANAKA, A., KOMATSU, Y., NISHINO, N., YOSHIDA, M. and HORINOUCHI, S. (2002). FK228 (depsipeptide) as a natural prodrug that inhibits class I histone deacetylases. Cancer Res. 62: 4916-4921.

GUARENTE, L. (2007). Sirtuins in aging and disease. Cold Spring Harb. Symp. Quant. Biol. 72: 483-8.

GUARENTE, L. and PICARD, F. (2005). Calorie restriction-the SIR2 connection. Cell 120: 473-82.

KAIDA, D., MOTOYOSHI, H., TASHIRO, E., NOJIMA, T., HAGIWARA, M., ISHIGAMI, K., WATANABE, H., KITAHARA, T., YOSHIDA, T., NAKAJIMA, H., TANI, T., HORINOUCHI, S. and YOSHIDA, M. (2007). Spliceostatin A targets SF3b and inhibits both splicing and nuclear retention of pre-mRNA. Nat. Chem. Biol. 3: 576-583.

KHOCHBIN, S., VERDEL, A., LEMERCIER, C. and SEIGNEURIN-BERNY, D. (2001). Functional significance of histone deacetylase diversity. Curr. Opin. Genet. Dev. 11: 162-166.

KUDO, N., KHOCHBIN, S., NISHI, K., KITANO, K., YANAGIDA, M., YOSHIDA, M. and HORINOUCHI, S. (1997). Molecular cloning and cell cycle-dependent expression of mammalian CRM1, a protein involved in nuclear export of proteins. J. Biol. Chem. 272: 29742-29751.

KUDO, N., MATSUMORI, N., TAOKA, H., FUJIWARA, D., SCHREINER, E.P., WOLFF, B., YOSHIDA, M. and HORINOUCHI, S. (1999). Leptomycin B inactivates CRM1/exportin 1 by covalent modification at a cysteine residue in the central conserved region. Proc. Natl. Acad. Sci. USA 96: 9112-9117.

LAVU, S., BOSS, O., ELLIOTT1, P. J., and LAMBERT, P. D. (2008). Sirtuins-novel therapeutic targets to treat age-associated diseases. Nat. Rev. Drug Discov. 7: 841-53.

LEE, M. G. and NURSE, P. (1987). Complementation used to clone a human homologue of the fission yeast cell cycle control gene cdc2. Nature 327: 31-35.

MARKS, P., RIFKIND, R. A., RICHON, V. M., BRESLOW, R., MILLER, T. and KELLY, W. K. (2001). Histone deacetylases and cancer: causes and therapies. Nat. Rev. Cancer 1: 194-202.

MATSUYAMA, A., SHIMAZU, T., SUMIDA, Y., SAITO, A., YOSHIMATSU, Y., SEIGNEURIN-BERNY, D., OSADA, H., KOMATSU, Y., NISHINO, N., KHOCHBIN, S., HORINOUCHI, S. and YOSHIDA, M. (2002). In vivo destabilization of dynamic microtubules by HDAC6-mediated deacetylation.
EMBO J. 21: 6820-6831.

NAKAJIMA, H., KIM, Y. B., TERANO, H., YOSHIDA, M. and HORINOUCHI, S. (1998). FR901228, a potent antitumor antibiotic, is a novel histone deacetylase inhibitor. Exp. Cell Res. 241: 126-133.

NAN, X., NG, H. H., JOHNSON, C. A., LAHERTY, C. D., TURNER, B. M., EISENMAN, R. N. and BIRD, A. (1998). Transcriptional repression by the methyl-CpG-binding protein MeCP2 involves a histone deacetylase complex. Nature 393: 386-389.

NISHI, K., YOSHIDA, M., FUJIWARA, D., NISHIKAWA, M., HORINOUCHI, S. and BEPPU, T. (1994). Leptomycin B targets a regulatory cascade of crm1, a fission yeast nuclear protein, involved in control of higher order chromosome structure and gene expression. J. Biol. Chem. 269: 6320-6324.

NURSE, P. and BISSETT, Y. (1981). Gene required in G1 for commitment to cell cycle and in G2 for control of mitosis in fission yeast Schizosaccharomyces pombe. Nature 292: 558-560.

ONYANGO, P., CELIC, I., MCCAFFERY, J. M., BOEKE, J. D. and FEINBERG, A.P. (2002). SIRT3, a human SIR2 homologue, is an NAD-dependent deacetylase localized to mitochondria. Proc Natl Acad Sci USA. 99: 13653-8.

OSSAREH-NAZARI, B., BACHELERIE, F. and DARGEMONT, C. (1997). Evidence for a role of CRM1 in signal-mediated nuclear protein export. Science 278: 141144.

PANDEY, U. B., NIE, Z., BATLEVI, Y., MCCRAY, B. A., RITSON, G. P., NEDELSKY, N. B., SCHWARTZ, S. L., DIPROSPERO, N. A., KNIGHT, M. A., SCHULDINER, O., PADMANABHAN, R., HILD, M., BERRY, D. L., GARZA, D., HUBBERT, C. C., YAO, T. P., BAEHRECKE, E. H. and TAYLOR, J. P. (2007). HDAC6 rescues neurodegeneration and provides an essential link between autophagy and the UPS. Nature 447: 859-63.

RICHON, V. M., EMILIANI, S., VERDIN, E., WEBB, Y., BRESLOW, R., RIFKIND, R. A. and MARKS, P.A. (1998). A class of hybrid polar inducers of transformed cell differentiation inhibits histone deacetylases. Proc. Natl. Acad. Sci. USA 95: 3003-3007.

SCHWER, B., NORTH, B. J., FRYE, R. A., OTT, M., and E., V. (2002). The human silent information regulator (Sir)2 homologue hSIRT3 is a mitochondrial nicotinamide adenine dinucleotide-dependent deacetylase. J. Cell Biol. 158: 647-57.

SEIGNEURIN, D., GRUNWALD, D., LAWRENCE, J. J., and KHOCHBIN, S. (1995). Developmentally regulated chromatin acetylation and histone $\mathrm{H} 1(0)$ accumulation. Int. J. Dev. Biol. 39: 597-603.

TAUNTON, J., HASSIG, C.A. and SCHREIBER, S.L. (1996). A mammalian histone deacetylase related to the yeast transcriptional regulator Rpd3p. Science 272: 408-411.

YANG, X. J. and SETO, E. (2008). The Rpd3/Hda1 family of lysine deacetylases: from bacteria and yeast to mice and men. Nat. Rev. Mol. Cell Biol. 9: 206-18.

YOSHIDA, M. and BEPPU, T. (1988). Reversible arrest of proliferation of rat 3Y1 fibroblasts in both the G1 and G2 phases by trichostatin A. Exp. Cell Res. 177: 122-131.

YOSHIDA, M., KIJIMA, M., AKITA, M. and BEPPU, T. (1990). Potent and specific inhibition of mammalian histone deacetylase both in vivo and in vitro by trichostatin A. J. Biol. Chem. 265: 17174-17179.

YOSHIDA, M., NOMURA, S. and BEPPU, T. (1987). Effects of trichostatins on differentiation of murine erythroleukemia cells. Cancer Res. 47: 3688-3691. 


\section{Further Related Reading, published previously in the Int. J. Dev. Biol.}

See our recent Special Issue Fertilization, in honor of David L. Garbers and edited by Paul M. Wassarman and Victor D. Vacquier at: http://www.ijdb.ehu.es/web/contents.php?vol=52\&issue=5-6

The Xenopus Bowline/Ripply family proteins negatively regulate the transcriptional activity of T-box transcription factors Keisuke Hitachi, Hiroki Danno, Shunsuke Tazumi, Yuko Aihara, Hideho Uchiyama, Koji Okabayashi, Akiko Kondow and Makoto Asashima Int. J. Dev. Biol. (2009) 53 doi: 10.1387/ijdb.082823kh

Multiple stage-dependent roles for histone deacetylases during amphibian embryogenesis: implications for the involvement of extracellular matrix remodeling.

S Damjanovski, L M Sachs and Y B Shi

Int. J. Dev. Biol. (2000) 44: 769-776

\section{Other IJDB Interviews}

Idealism and romantic patriotism for science - an interview with José Francisco David-Ferreira Maria Carmo-Fonseca and José Francisco David-Ferreira Int. J. Dev. Biol. in press

Early mammalian embryo: my love. An interview with Andrzej K. Tarkowski

Marek Maleszewski

Int. J. Dev. Biol. (2008) 52: 163-169

In pursuit of communication. An interview with Bob Ruben

Fernando Giraldez and Bernd Fritzsch

Int. J. Dev. Biol. (2007) 51: 439-445

From observations to paradigms; the importance of theories and models. An interview with Hans Meinhardt

Richard Gordon and Lev Beloussov

Int. J. Dev. Biol. (2006) 50: 103-111

A life in research on lens regeneration and transdifferentiation. An interview with Goro Eguchi

Kunio Yasuda

Int. J. Dev. Biol. (2004) 48: 695-700

Discovery and characterization of the cadherin family of cell adhesion molecules. An interview with Masatoshi Takeichi.

Douglas Sipp

Int. J. Dev. Biol. (2004) 48: 387-396

The extracellular matrix in development and regeneration. An interview with Elizabeth $D$. Hay

Robert L. Trelstad

Int. J. Dev. Biol. (2004) 48: 687-694

Tumor invasion and metastasis: getting more basic to come closer to the patient. An interview with Lance A. Liotta.

Vincent Castronovo

Int. J. Dev. Biol. (2004) 48: 559-562

The migration and differentiation of a chemist entangled in developmental and cancer biology. An interview with Jean-Paul Thiery.

Fred T. Bosman

Int. J. Dev. Biol. (2004) 48: 529-535

2006 ISI **Impact Factor $=3.577^{* *}$

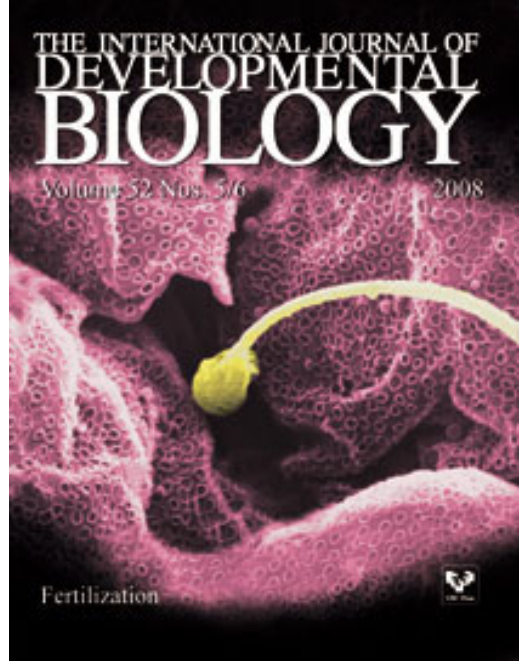

